\title{
Phytochemicals from Cocoa Shell Protect Mitochondrial Function and Alleviate Oxidative Stress in Hepatocytes via Regulation of ERK and PI3K-AKT Pathways ${ }^{+}$
}

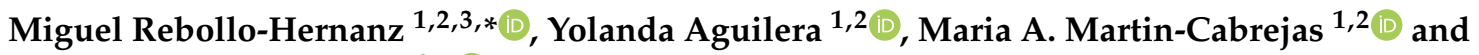 \\ Elvira Gonzalez de Mejia ${ }^{3, *(D)}$ \\ 1 Department of Agricultural Chemistry and Food Science, Universidad Autónoma de Madrid, \\ 28049 Madrid, Spain; yolanda.aguilera@uam.es (Y.A.); maria.martin@uam.es (M.A.M.-C.) \\ 2 Institute of Food Science Research, CIAL (UAM-CSIC), 28049 Madrid, Spain \\ 3 Department of Food Science and Human Nutrition, University of Illinois at Urbana-Champaign, \\ Urbana, IL 61801, USA \\ * Correspondence: miguel.rebollo@uam.es (M.R.-H.); edemejia@illinois.edu (E.G.d.M.); \\ Tel.: +1-217-244-3196 (E.G.d.M.) \\ + Presented at the 1st International E-Conference on Antioxidants in Health and Disease, 1-15 December 2020; \\ Available online: https://cahd2020.sciforum.net/.
}

Citation: Rebollo-Hernanz, M.; Aguilera, Y.; Martin-Cabrejas, M.A.; de Mejia, E.G. Phytochemicals from Cocoa Shell Protect Mitochondrial Function and Alleviate Oxidative Stress in Hepatocytes via Regulation of ERK and PI3K-AKT Pathways. Med. Sci. Forum 2021, 2, 25. https:// doi.org/10.3390/msf2021002025

Academic Editor: Mihalis I.

Panagiotidis

Published: 22 July 2021

Publisher's Note: MDPI stays neutral with regard to jurisdictional claims in published maps and institutional affiliations.

Copyright: (C) 2021 by the authors Licensee MDPI, Basel, Switzerland. This article is an open access article distributed under the terms and conditions of the Creative Commons Attribution (CC BY) license (https:// creativecommons.org/licenses/by/ $4.0 /)$.

\begin{abstract}
This research aimed to assess the impact of an aqueous extract from the cocoa shell and its major phytochemicals on preventing oxidative stress and mitochondrial dysfunction in hepatocytes using an in vitro model of nonalcoholic fatty liver disease (NAFLD). The phytochemicals from cocoa shell were extracted using water and characterized by UPLC-MS/MS analysis. HepG2 cells were cotreated with either the aqueous extract from cocoa shell (CAE, 20-100 $\mu \mathrm{g} \mathrm{mL}^{-1}$ ) or 10-50 $\mu \mathrm{mol} \mathrm{L}^{-1}$ of pure theobromine, protocatechuic acid, procyanidin B2, epicatechin, and catechin in the presence or absence of palmitic acid (PA, $500 \mu \mathrm{mol} \mathrm{L}^{-1}$ ) to mimic NAFLD conditions in vitro. Biomarkers of mitochondrial function and oxidative stress were evaluated $24 \mathrm{~h}$ after the cotreatment in cell supernatants and lysates using chemical, biochemical, and immunochemical techniques. CAE and the phytochemicals therein significantly $(p<0.05)$ protected mitochondrial content $(15-100 \%)$ and preserved mitochondrial function, promoting $\mathrm{O}_{2}$ consumption (1.2- to 1.8-fold) and ATP production (1.3- to 2.1-fold). Phytochemicals from cocoa shell significantly $(p<0.05)$ decreased PA-triggered oxidative stress. The mitochondrial membrane potential was maintained (62-100\%), and the production of mitochondrial superoxide (26-100\%) and total ROS (17-100\%) was abrogated. CAE significantly $(p<0.05)$ modulated cell signaling pathways associated with ROS production and mitochondrial dysfunction, including an increase in the phosphorylation of ERK1/2 (2.8-fold), protein kinase B (AKT) (2.8-fold), GSK3 (2.3-fold), Raf-1 (1.9-fold), and mTOR (1.7-fold). In conclusion, results suggested that the cocoa shell's phytochemicals could protect mitochondrial liver function and alleviate oxidative stress by modulating key pathways involved in their regulation.
\end{abstract}

Keywords: cocoa shell; cocoa by-products; antioxidants; theobromine; phenolic compounds; phytochemicals; nonalcoholic fatty liver disease; oxidative stress; ROS; mitochondrial function

\section{Introduction}

The World Health Organization pinpoints chronic diseases as responsible for $71 \%$ of all deaths worldwide [1]. Metabolic disorders are caused by defective cellular metabolic processes triggering energy and redox imbalances and the induction of many pathophysiological conditions. The main hallmarks of metabolic disorders include obesity, insulin resistance, type 2 diabetes mellitus, hypertension, hyperlipidemia, and metabolic syndrome [2]. These conditions involve the development of nonalcoholic fatty liver disease (NAFLD), a disorder defined by excessive fat accumulation in the form of triglycerides 
(steatosis) in the liver [3]. The global prevalence of NAFLD is currently estimated to be $24 \%$ [4]. These diseases could be prevented through nutrition and adequate food patterns [5]. Cocoa shell is the main by-product of cocoa production (12-20\% of cocoa seed) separated from the bean during the roasting process, generated in approximately 700 thousand tons a year, and was initially considered waste [6]. In our previous studies [7,8], we demonstrated the applicability of phytochemicals extracted from cocoa shell in the modulation of inflammation, insulin resistance, and mitochondrial function in adipocytes. The use of cocoa by-products as a source of biologically active phytochemicals can be considered a sustainable health promotion strategy for disease prevention. Hence, this work aimed to evaluate the potential of an extract from cocoa shell and its pure phytochemicals on the modulation of metabolic syndrome-related biomarkers associated with oxidative stress and mitochondrial function of hepatocytes in vitro using a model of NAFLD.

\section{Experiments}

\subsection{Materials}

Minimum essential medium (MEM) was purchased from Corning (Manassas, VA, USA); fetal bovine serum (FBS), penicillin-streptomycin (100×), and $0.25 \%$ trypsin-EDTA were obtained from Gibco Life Technologies (Grand Island, NY, USA). Pure bioactive compounds (purity $\geq 96 \%$ ), including caffeine, chlorogenic acid, caffeic acid, protocatechuic acid, gallic acid, and kaempferol, were purchased from Sigma-Aldrich (St. Louis, MO, USA) and Extrasynthese (Genay, France).

\subsection{Aqueous Extraction of Phytochemicals from Cocoa Shell and UPLC-MS/MS Characterization}

The cocoa shell was supplied by Chocolates Santocildes (Castrocontrigo, León, Spain). Based on previous extraction protocols [9], a phenolic aqueous extract from cocoa shell was prepared. After milling and sieving, the ground cocoa shell $(10 \mathrm{~g})$ was added into $500 \mathrm{~mL}$ of boiling water $\left(100^{\circ} \mathrm{C}\right)$ and stirred for $90 \mathrm{~min}$. The cocoa shell aqueous extract (CAE) was filtered and frozen at $-20^{\circ} \mathrm{C}$ for $24 \mathrm{~h}$. The extract was freeze-dried and stored at $-20^{\circ} \mathrm{C}$ until further use. The targeted phytochemical analysis was carried out using UPLC-ESI-MS/MS following a method previously described [8].

\subsection{Cell Culture}

The HepG2 human hepatocyte cell line obtained from the American Type Culture Collection (Manassas, VA, USA) was grown at $37{ }^{\circ} \mathrm{C}$ in an atmosphere of $5 \% \mathrm{CO}_{2}$. HepG2 cells were cultured in MEM supplemented with $10 \%$ FBS, $1 \%$ penicillin-streptomycin, and $1 \%$ sodium pyruvate. Cells were plated at a density of $10^{5}$ cells $\mathrm{cm}^{-2}$ flask.

\subsection{Experimental Design}

Hepatocytes were treated with pure phytochemicals (theobromine, protocatechuic acid, epicatechin, procyanidin B2, and catechin) from cocoa shell $\left(10,20\right.$, or $\left.50 \mu \mathrm{mol} \mathrm{L}^{-1}\right)$ or CAE (20,50, $\left.100 \mu \mathrm{g} \mathrm{mL}^{-1}\right)$ in the presence or absence of palmitic acid (PA, $500 \mu \mathrm{mol} \mathrm{L}^{-1}$ ) for $24 \mathrm{~h}$. Supernatants were collected and stored at $-80^{\circ} \mathrm{C}$ until further analysis. Cells were washed twice with ice-cold PBS, lysed using the RIPA Lysis Buffer System (Santa Cruz Biotechnology, Santa Cruz, CA, USA), and centrifuged at $10,000 \times g$ and $4{ }^{\circ} \mathrm{C}$ for $10 \mathrm{~min}$ to eliminate cell debris before storage at $-80^{\circ} \mathrm{C}$.

\subsection{Cell Viability}

Viability of cells treated with pure phytochemicals from cocoa shell $(10,20$, or $\left.50 \mu \mathrm{mol} \mathrm{L}{ }^{-1}\right)$ or CAE $\left(20,50\right.$, or $\left.100 \mu \mathrm{g} \mathrm{mL}^{-1}\right)$ in the presence or absence of palmitic acid $\left(500 \mu \mathrm{mol} \mathrm{L}^{-1}\right)$ for $24 \mathrm{~h}$ was assessed with the CellTiter 96 Aqueous One Solution Proliferation assay (Promega Corporation, Madison, WI, USA) following manufacturer's instructions. 
2.6. Evaluation of the Effect of Phytochemicals from Cocoa Shell Intracellular ROS, Mitochondrial Superoxide, and Mitochondrial Membrane Potential $(\Delta \Psi m)$

ROS production was measured after the treatment with palmitic acid $\left(500 \mu \mathrm{mol} \mathrm{L}{ }^{-1}\right)$ and pure phytochemicals $\left(10,20\right.$, or $\left.50 \mu \mathrm{mol} \mathrm{L}^{-1}\right)$ or CAE $\left(20,50\right.$, or $\left.100 \mu \mathrm{g} \mathrm{mL}^{-1}\right)$ for $24 \mathrm{~h}$. The cells were incubated for $1 \mathrm{~h}$ with MEM supplemented with $2^{\prime}, 7^{\prime}$-dichlorodihydrofluorescein diacetate (DCFDA, $25 \mu \mathrm{mol} \mathrm{L}{ }^{-1}$ ). The cells were then washed with PBS, and the fluorescence was detected at excitation and emission wavelengths of 485 and $535 \mathrm{~nm}$, respectively. Mitochondrial superoxide was detected by incubating treated cells with Mitosox Red (Invitrogen Molecular Probes, Carlsbad, CA, USA), measuring fluorescence at an excitation wavelength of $510 \mathrm{~nm}$ and an emission wavelength of $580 \mathrm{~nm}$. Mitochondrial membrane potential $(\triangle \Psi \mathrm{m})$ was determined using the mitochondria-specific fluorescence die, JC-1 (Thermo Fisher, Skokie, IL, USA), following the manufacturer's instructions. JC-1 aggregates were detected at 550/590 nm (excitation/emission), while JC-1 monomers were detected at 485/535 $\mathrm{nm}$ (excitation/emission). The JC- 1 aggregates/monomers ratio was calculated for each condition as an indicator of mitochondrial functionality [10].

2.7. Evaluation of the Effect of Phytochemicals from Cocoa Shell on Hepatic Mitochondrial Content, Oxygen Consumption, and ATP Production

After the treatment with palmitic acid $\left(500 \mu \mathrm{mol} \mathrm{L}^{-1}\right)$ and pure phytochemicals $(10$, 20 , or $\left.50 \mu \mathrm{mol} \mathrm{L}^{-1}\right)$ or CAE $(20,50$, or $100 \mu \mathrm{g} \mathrm{mL}-1)$ for $24 \mathrm{~h}$, mitochondrial content was determined using MitoTracker Green (MitoTracker Deep Green FM, Invitrogen, Waltham, MA, USA). Fluorescence intensity was measured at excitation and emission wavelengths of 644 and $665 \mathrm{~nm}$, respectively. Oxygen consumption rate (OCR) is one of the most informative and direct measures of mitochondrial function and was measured using a kit according to the manufacturer's instructions (ab197243; Abcam, Cambridge, UK). According to the manufacturer's instructions, the ATP content was measured in cell lysates using an ATP detection assay kit (Cayman Chemical, No. 700410, Ann Arbor, MI, USA).

2.8. Evaluation of the Effect of Phytochemicals from Cocoa Shell on the Phosphorylation Pattern of Liver Cellular Key Signaling Pathways

HepG2 hepatocytes were cultured and treated with palmitic acid $\left(500 \mu \mathrm{mol} \mathrm{L}^{-1}\right)$ in the presence/absence of CAE $\left(100 \mu \mathrm{g} \mathrm{mL}{ }^{-1}\right)$ for $24 \mathrm{~h}$. After treatment, the cells were serum-starved for $30 \mathrm{~min}$, followed by $10 \mathrm{~min}$ stimulation with $10 \mathrm{ng} \mathrm{mL} \mathrm{H}^{-1}$ insulin. Cell lysates were applied following the manufacturer's instructions to insulin receptor and AKT signaling pathway microarrays (RayBiotech, AAH-INSR and AAH-AKT). Array signals were visualized on a GelLogic 4000 Pro Imaging System (Carestream Health, Inc., Rochester, NY, USA).

\subsection{Bioinformatic Analysis}

The resulting differentially phosphorylated proteins and protein-protein interactions were searched using Metascape (https: / / metascape.org/, accessed on 24 September 2020) [11]. The differentially expressed proteins were categorized based on the biological process and molecular function and further analyzed through Kyoto Encyclopedia of Genes and Genomes (KEGG) pathway enrichment analysis by using the KEGG database (http:/ / www.genome.jp/kegg/kaas/, accessed on 24 September 2020). Enrichment analysis and protein-protein interaction networks of the studied proteins and their nearest functional and predicted associations were established.

\subsection{Statistical Analysis}

Sample preparation and determinations were performed in triplicate. Results are expressed as the mean \pm standard deviation (SD) $(n=3)$ and were analyzed by one-way analysis of variance (ANOVA) and post hoc Tukey test. Differences were considered significant at $p<0.05$. The statistical analysis of the results was performed using SPSS 24.0. Multivariate analyses were carried out with XLSTAT 2018 for Microsoft Excel 2016. 


\section{Results}

\subsection{Cocoa Shell Was Mainly Composed of Theobromine, Protocatechuic Acid, and Flavan-3-Ols}

A comprehensive UPLC-MS/MS analysis of the polyphenolic profile of the CAE showed cocoa shell was primarily composed of theobromine and caffeine, the main phenolics being protocatechuic acid and flavan-3-ols, both monomers ((+)-catechin and (-)epicatechin) and dimers (procyanidin B2). Thus, these phytochemicals were selected as phenolics for further analyses. None of the treatments, CAE $\left(20,50\right.$, or $\left.100 \mu \mathrm{g} \mathrm{mL}{ }^{-1}\right)$ or pure compounds $\left(10,20\right.$, or $\left.50 \mu \mathrm{mol} \mathrm{L}^{-1}\right)$, exerted cytotoxicity in HepG2 hepatocytes at the concentrations tested $(p>0.05)$. Only the results at the highest concentrations tested are being reported $\left(100 \mu \mathrm{g} \mathrm{mL} \mathrm{g}^{-1}\right.$ and $50 \mu \mathrm{mol} \mathrm{L}^{-1}$ for CAE and the pure compounds, respectively).

\subsection{Phytochemicals Present in Cocoa Shell Attenuated Oxidative Stress in Palmitic Acid Treated Hepatocytes}

Phytochemicals from cocoa shell significantly $(p<0.05)$ decreased palmitic acid triggered oxidative stress (Figure 1A,B). The production of mitochondrial superoxide (26-100\%) and total ROS (17-100\%) was abrogated (Figure 1A), and the mitochondrial membrane potential $(\Delta \Psi \mathrm{m})$ was maintained $(62-100 \%)$ (Figure 1B). While epicatechin was the bioactive compound exhibiting the highest potential in preventing ROS production, theobromine maintained the $\Delta \Psi \mathrm{m}$ at a level comparable to that of the healthy state control. The effect of $\mathrm{CAE}$ was similar to that of the pure compounds. Considering the lower concentration of phytochemicals present in it, additive or synergetic effects might be occurring among the phenolics and alkaloids composing the extract.

A
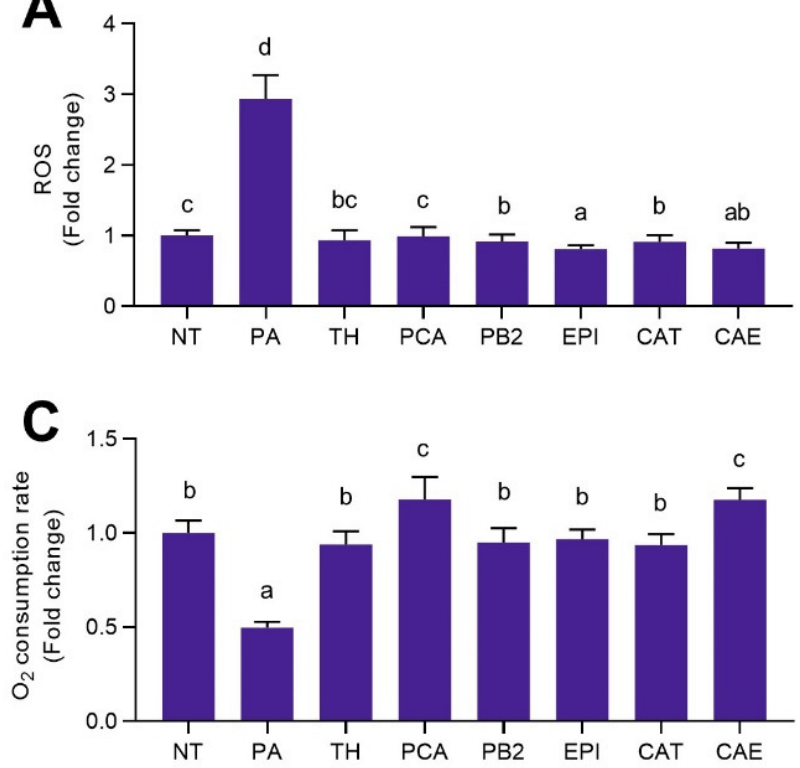

B

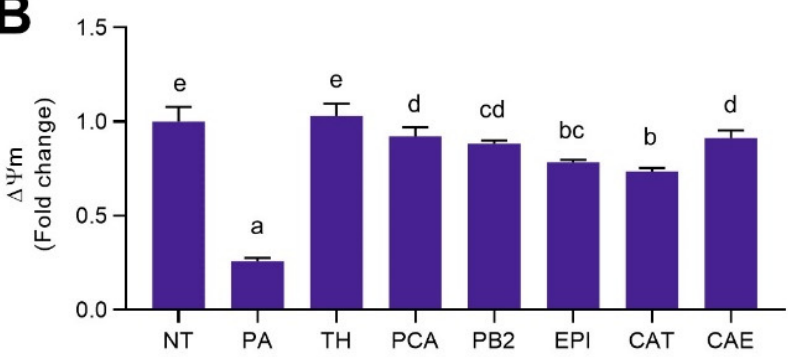

D

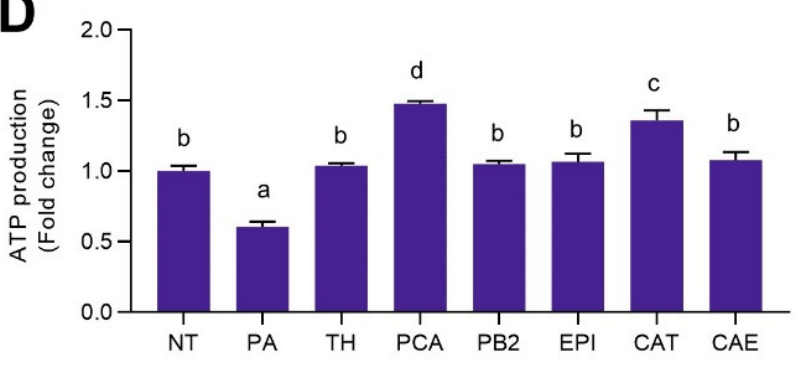

Figure 1. Protective effects of pure phytochemicals from cocoa shell $\left(50 \mu \mathrm{mol} \mathrm{L}^{-1}\right)$ or aqueous extract $(\mathrm{CAE})\left(100 \mu \mathrm{g} \mathrm{mL}{ }^{-1}\right)$ in the presence or absence of palmitic acid $\left(500 \mu \mathrm{mol} \mathrm{L}{ }^{-1}\right)$ against oxidative stress and the loss of mitochondrial function in HepG2 human hepatocytes. Phytochemicals from cocoa shell reduced the production of ROS (A) while maintaining the mitochondrial membrane potential $(\Delta \Psi \mathrm{m})(\mathbf{B})$ in palmitic acid treated hepatocytes. Oxygen consumption rate $(\mathbf{C})$ and ATP production (D) were thereby protected. The results are expressed as mean $\pm \operatorname{SD}(n=3)$. Bars with different letters significantly $(p<0.05)$ differ according to ANOVA and Tukey's multiple range test. NT: nontreated cells; PA: palmitic acid; TH: theobromine; PCA: protocatechuic acid; PB2: procyanidin B2; EPI: epicatechin; CAT: catechin. 


\subsection{Phytochemicals from Cocoa Shell Counteracted Palmitic Acid Effects on Mitochondrial Function in Hepatocytes}

Phytochemicals from cocoa shell and CAE significantly $(p<0.05)$ protected mitochondrial content (15-100\%) and preserved mitochondrial function, promoting $\mathrm{O}_{2}$ consumption (1.2- to 1.8-fold) and ATP production (1.3- to 2.1-fold) (Figure 1C,D). Oxygen consumption rate was preserved in palmitic acid treated hepatocytes or even augmented (by protocatechuic acid and CAE), demonstrating the regulative effects of cocoa shell phytochemicals on mitochondrial bioenergetics. Likewise, the production of ATP was enhanced upon stimulation with palmitic acid. All pure compounds prevented the reduced ATP production caused by palmitic acid, and protocatechuic acid and catechin even prompted ATP production.

\subsection{Phytochemicals from Cocoa Shell Protect Mitochondrial Function and Alleviate Oxidative Stress in Hepatocytes via Regulation of ERK and PI3K-AKT Pathways}

To better comprehend the molecular mechanism governing the regulations previously observed on oxidative stress and mitochondrial function, the phosphorylation pattern of multiple proteins associated with cell signaling was studied. CAE significantly $(p<0.05)$ modulated the phosphorylation of 20 out of 30 studied proteins. CAE regulated cell signaling pathways associated with ROS production and mitochondrial dysfunction, including an increase in the phosphorylation of ERK1/2 (2.8-fold), protein kinase B (AKT) (2.8-fold), GSK3 (2.3-fold), Raf-1 (1.9-fold), and mTOR (1.7-fold). Protein-protein interaction corroborated the relationship established among proteins from the same pathway (Figure 2A). CAE up-phosphorylated proteins were clustered in three groups (ERK, AKT, and insulin pathways). The most significant biological pathways regulated by the effect of phosphorylation modulation by CAE included PI3K-AKT, mTOR, insulin, ERK, FOXO, and AMPK pathways (Figure 2B).
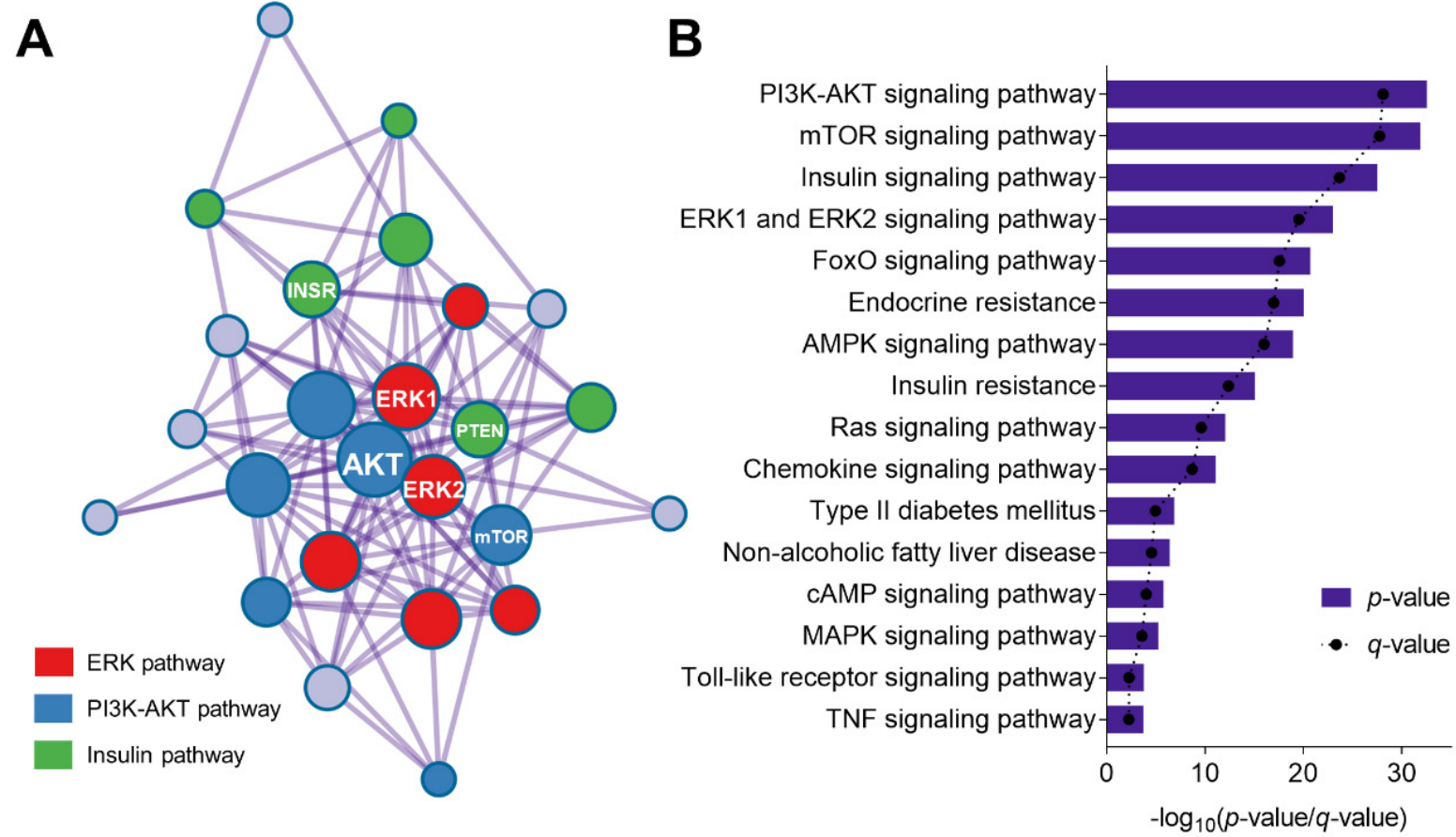

Figure 2. Cocoa shell phytochemicals differentially modulated the phosphorylation of proteins associated with cell signaling pathways with key effects on ROS and mitochondrial function. Protein-protein interaction networks built with Metascape from the differentially phosphorylated protein in hepatocytes by the cotreatment of HepG2 cells with palmitic acid $\left(500 \mu \mathrm{mol} \mathrm{L}^{-1}\right)$ and CAE $\left(100 \mu \mathrm{g} \mathrm{mL}^{-1}\right)$ (using cells only treated with palmitic acid as a control) (A) and KEGG pathways associated with the differentially phosphorylated proteins $(\mathbf{B})$. 


\section{Discussion}

The global obesity epidemic is accompanied by an increasing prevalence of associated metabolic disorders [12]. For the first time, we present the impact of a well-characterized theobromine- and phenolic-rich extract from cocoa shell and five pure bioactive compounds (one alkaloid and four phenolics), assessing them in an in vitro model of NAFLD. The mentioned disease is characterized by a dysregulated hepatic metabolism conducive to insulin resistance, lipid accumulation, and further inflammation and oxidative stress [13]. The use of food-based strategies to prevent metabolic diseases has been previously evidenced. We previously demonstrated the modulatory activity of bioactive compounds from cocoa shell on obesity-related inflammation in adipocytes and the alleviation of mitochondrial dysfunction and insulin resistance [7]. The cocoa shell has recently been validated as a sustainable and safe novel antioxidant food ingredient, allowing it to be incorporated in the development of foods with health-promoting properties [14]. In this report, we observed reduced production of ROS, indicating less damage to mitochondria. Although pro- and antioxidant effects could be occurring, the balance resulted in an antioxidant effect, as observed by the reduction of total ROS and mitochondrial superoxide. Recent evidence suggests that NAFLD might be a mitochondrial disease [15]. NAFLD has been shown to be associated with reduced mitochondrial function, decreased mitochondrial size, reduced mitochondrial density, reduced activity of mitochondrial enzymes, lower expression of oxidative phosphorylation genes, and lower ATP production [15]. Mitochondrial dysfunction contributes to NAFLD's pathogenesis since it affects hepatic lipid homeostasis and promotes ROS production, lipid peroxidation, cytokine release, and cell death [16]. Previous studies demonstrated the potential effects of cocoa phytochemicals on hepatic metabolism via activation of the FGF21 signaling cascade [17], which could be associated with NAFLD prevention. Cell metabolic signaling regulation leads to a more functional phenotype in HepG2 cells than palmitic acid treated control. The activation of ERK and AKT pathways has been associated with the induction of Nrf2-mediated antioxidative cellular defenses $[18,19]$. Furthermore, ERK and AKT pathways have been associated with the free fatty acid derived loss of mitochondrial function in hepatocytes $[20,21]$. Hence, phytochemicals from cocoa shell may be abrogating the adverse effects caused by palmitic acid on the oxidative status and mitochondrial function via the regulation of these two major pathways. Despite the potential biological activity of phytochemicals from cocoa shell, the bioefficacy of phenolic compounds is conditioned by their low bioavailability [22]. These phytochemicals are only partially absorbed in the gastrointestinal tract. Phytochemicals' effect could be somewhat altered after being metabolized by the microbiota or the liver (methylation, sulfation, and glucuronidation) [23]. Future animal and clinical investigations will be necessary to confirm the effects observed in vitro and determine the absorption and metabolism of cocoa shell phytochemicals and their beneficial and potentially harmful effects.

\section{Conclusions}

In conclusion, our results evidenced that phytochemicals from cocoa shell, mainly theobromine and protocatechuic acid, could regulate oxidative stress and mitochondrial function in hepatocytes under palmitic acid stimulation. Moreover, we provide new knowledge of the bioactive compounds responsible for cocoa shell's underlying mechanism of action. Overall, our results generate new insights into cocoa shell used as a sustainable food ingredient to counter NAFLD.

Author Contributions: Conceptualization, M.R.-H. and E.G.d.M.; formal analysis, M.R.-H.; investigation, M.R.-H.; data curation, M.R.-H.; writing—original draft preparation, M.R.-H.; writing—review and editing, M.R.-H., Y.A., M.A.M.-C., and E.G.d.M.; visualization, M.R.-H. and Y.A.; supervision, Y.A., M.A.M.-C., and E.G.d.M.; funding acquisition, Y.A., M.A.M.-C., and E.G.d.M. All authors have read and agreed to the published version of the manuscript. 
Funding: This research was funded by the USDA-NIFA-HATCH project to E.G.d.M. (1014457) and by the COCARDIOLAC project from the Spanish Ministry of Science and Innovation (RTI 2018-097504-B-I00). M. Rebollo-Hernanz received funding from the FPU program of the Ministry of Universities for his predoctoral fellowship (FPU15/04238) and the support for the international research stays at the University of Illinois, Urbana-Champaign (EST17/00823, EST18/0064).

Institutional Review Board Statement: Not applicable.

Informed Consent Statement: Not applicable.

Data Availability Statement: The data presented in this study are available on request from the corresponding author on reasonable request.

Conflicts of Interest: The authors declare no conflict of interest.

$\begin{array}{ll}\text { Abbreviations } \\ \text { NT } & \text { Nontreated cells } \\ \text { PA } & \text { Palmitic acid } \\ \text { PB2 } & \text { Procyanidin B2 } \\ \text { PBS } & \text { Phosphate-buffered saline } \\ \text { PCA } & \text { Protocatechuic acid } \\ \text { ROS } & \text { Reactive oxygen species } \\ \text { TH } & \text { Theobromine } \\ \text { CAE } & \text { Cocoa shell aqueous extract } \\ \text { CAT } & \text { Catechin } \\ \text { EDTA } & \text { Ethylenediaminetetraacetic acid } \\ \text { EPI } & \text { Epicatechin } \\ \text { FBS } & \text { Fetal bovine serum } \\ \text { MEM } & \text { Minimum essential medium } \\ \text { NAFLD } & \text { Nonalcoholic fatty liver disease }\end{array}$

\section{References}

1. World Health Organization Noncommunicable Diseases. Available online: https://www.who.int/news-room/fact-sheets/ detail/noncommunicable-diseases (accessed on 20 May 2020).

2. Rani, V.; Deep, G.; Singh, R.K.; Palle, K.; Yadav, U.C.S. Oxidative stress and metabolic disorders: Pathogenesis and therapeutic strategies. Life Sci. 2016, 148, 183-193. [CrossRef] [PubMed]

3. Abd El-Kader, S.M.; El-Den Ashmawy, E.M.S. Non-alcoholic fatty liver disease: The diagnosis and management. World J. Hepatol. 2015, 7, 846-858. [CrossRef] [PubMed]

4. Younossi, Z.; Anstee, Q.M.; Marietti, M.; Hardy, T.; Henry, L.; Eslam, M.; George, J.; Bugianesi, E. Global burden of NAFLD and NASH: Trends, predictions, risk factors and prevention. Nat. Rev. Gastroenterol. Hepatol. 2018, 15, 11-20. [CrossRef]

5. Schulze, M.B.; Martínez-González, M.A.; Fung, T.T.; Lichtenstein, A.H.; Forouhi, N.G. Food based dietary patterns and chronic disease prevention. BMJ 2018, 361, k2396. [CrossRef] [PubMed]

6. Panak Balentić, J.; Ačkar, Đ.; Jokić, S.; Jozinović, A.; Babić, J.; Miličević, B.; Šubarić, D.; Pavlović, N. Cocoa Shell: A By-Product with Great Potential for Wide Application. Molecules 2018, 23, 1404. [CrossRef]

7. Rebollo-Hernanz, M.; Zhang, Q.; Aguilera, Y.; Martín-Cabrejas, M.A.; de Mejia, E.G. Cocoa Shell Aqueous Phenolic Extract Preserves Mitochondrial Function and Insulin Sensitivity by Attenuating Inflammation between Macrophages and Adipocytes In Vitro. Mol. Nutr. Food Res. 2019, 63, 1801413. [CrossRef]

8. Rebollo-Hernanz, M.; Zhang, Q.; Aguilera, Y.; Martín-Cabrejas, M.A.; de Mejia, E.G. Relationship of the phytochemicals from coffee and cocoa by-products with their potential to modulate biomarkers of metabolic syndrome in vitro. Antioxidants 2019, 8, 279. [CrossRef]

9. Rebollo-Hernanz, M.; Cañas, S.; Taladrid, D.; Bartolomé, B.; Aguilera, Y.; Martin-Cabrejas, M.A. Extraction of phenolic compounds from cocoa shell: Modeling using response surface methodology and artificial neural networks. Sep. Purif. Technol. 2021, 270, 118779. [CrossRef]

10. Rebollo-Hernanz, M.; Zhang, Q.; Aguilera, Y.; Martín-Cabrejas, M.A.; Gonzalez de Mejia, E. Phenolic compounds from coffee by-products modulate adipogenesis-related inflammation, mitochondrial dysfunction, and insulin resistance in adipocytes, via insulin/PI3K/AKT signaling pathways. Food Chem. Toxicol. 2019, 132, 110672. [CrossRef] [PubMed]

11. Zhou, Y.; Zhou, B.; Pache, L.; Chang, M.; Khodabakhshi, A.H.; Tanaseichuk, O.; Benner, C.; Chanda, S.K. Metascape provides a biologist-oriented resource for the analysis of systems-level datasets. Nat. Commun. 2019, 10, 1523. [CrossRef]

12. Reilly, S.M.; Saltiel, A.R. Adapting to obesity with adipose tissue inflammation. Nat. Rev. Endocrinol. 2017, 13, 633-643. [CrossRef] 
13. Godoy-Matos, A.F.; Silva Júnior, W.S.; Valerio, C.M. NAFLD as a continuum: From obesity to metabolic syndrome and diabetes. Diabetol. Metab. Syndr. 2020, 12, 60. [CrossRef]

14. Rebollo-Hernanz, M.; Cañas, S.; Aguilera, Y.; Benitez, V.; Gila-Díaz, A.; Rodriguez-Rodriguez, P.; Cobeta, I.M.; de Pablo, A.L.L.; Gonzalez, M.C.; Arribas, S.M. Validation of Cocoa Shell as a Novel Antioxidant Dietary Fiber Food Ingredient: Nutritional Value, Functional Properties, and Safety. Curr. Dev. Nutr. 2020, 4, 773. [CrossRef]

15. Nassir, F.; Ibdah, J.A. Role of mitochondria in nonalcoholic fatty liver disease. Int. J. Mol. Sci. 2015, 15, 8713-8742. [CrossRef] [PubMed]

16. Begriche, K.; Igoudjil, A.; Pessayre, D.; Fromenty, B. Mitochondrial dysfunction in NASH: Causes, consequences and possible means to prevent it. Mitochondrion 2006, 6, 1-28. [CrossRef]

17. Rebollo-Hernanz, M.; Willis, L.; Aguilera, Y.; Martin-Cabrejas, M.A.; Gonzalez de Mejia, E. Fibroblast Growth Factor 21 Signaling Activation by Selected Bioactive Compounds from Cocoa Shell Modulated Metabolism and Mitochondrial Function in Hepatocytes. Curr. Dev. Nutr. 2020, 4, 459. [CrossRef]

18. Lv, H.; Ren, H.; Wang, L.; Chen, W.; Ci, X. Lico A Enhances Nrf2-Mediated Defense Mechanisms against t-BHP-Induced Oxidative Stress and Cell Death via Akt and ERK Activation in RAW 264.7 Cells. Oxid. Med. Cell. Longev. 2015, 2015, 709845. [CrossRef] [PubMed]

19. Jasek-Gajda, E.; Jurkowska, H.; Jasińska, M.; Lis, G.J. Targeting the MAPK/ERK and PI3K/AKT Signaling Pathways Affects NRF2, Trx and GSH Antioxidant Systems in Leukemia Cells. Antioxidants 2020, 9, 633. [CrossRef] [PubMed]

20. Li, Y.; Ding, H.; Liu, L.; Song, Y.; Du, X.; Feng, S.; Wang, X.; Li, X.; Wang, Z.; Li, X.; et al. Non-esterified Fatty Acid Induce Dairy Cow Hepatocytes Apoptosis via the Mitochondria-Mediated ROS-JNK/ERK Signaling Pathway. Front. Cell Dev. Biol. 2020, 8, 245. [CrossRef]

21. Dou, X.; Ding, Q.; Lai, S.; Jiang, F.; Song, Q.; Zhao, X.; Fu, A.; Moustaid-Moussa, N.; Su, D.; Li, S. Salidroside alleviates lipotoxicity-induced cell death through inhibition of TLR4/MAPKs pathway, and independently of AMPK and autophagy in AML-12 mouse hepatocytes. J. Funct. Foods 2020, 65, 103691. [CrossRef]

22. Kim, J.; Kim, J.; Shim, J.; Lee, C.Y.; Lee, K.W.; Lee, H.J. Cocoa Phytochemicals: Recent Advances in Molecular Mechanisms on Health. Crit. Rev. Food Sci. Nutr. 2014, 54, 1458-1472. [CrossRef] [PubMed]

23. Bohn, T.; Mcdougall, G.J.; Alegría, A.; Alminger, M.; Arrigoni, E.; Aura, A.M.; Brito, C.; Cilla, A.; El, S.N.; Karakaya, S.; et al. Mind the gap-deficits in our knowledge of aspects impacting the bioavailability of phytochemicals and their metabolites-a position paper focusing on carotenoids and polyphenols. Mol. Nutr. Food Res. 2015, 59, 1307-1323. [CrossRef] [PubMed] 